\title{
Erratum to: Application of Green Manure and Pig Manure to Cd-Contaminated Paddy Soil Increases the Risk of Cd Uptake by Rice and Cd Downward Migration into Groundwater: Field Micro-Plot Trials
}

\author{
Genmei Wang • Lixiang Zhou
}

Published online: 25 March 2017

(C) Springer International Publishing Switzerland 2017

\section{Erratum to: Water Air Soil Pollut \\ DOI 10.1007/s11270-016-3207-2}

In the original publication, an important funding acknowledgement was regretably not included. This article was funded by the Priority Academic Program Development of Jiangsu Higher Education Institutions (PAPD).

The online version of the original article can be found at http://dx. doi.org/10.1007/s11270-016-3207-2

G. Wang

College of Biology and the Environment, Nanjing Forestry

University, Nanjing 210037, China

e-mail: wangyinmei519@163.com

G. Wang $\cdot$ L. Zhou $(\bowtie)$

College of Resource and Environmental Sciences, Nanjing

Agricultural University, Nanjing 210095, China

e-mail:1xzhou@njau.edu.cn 